\title{
Using Fuzzy Delphi Method to Construct Digital Literacy Competences for Junior High School Students
}

\author{
Fuh-Gwo Chen, Jr-Shian Chen, Jen-Ya Wang, and David Wen-Shung Tai
}

\begin{abstract}
The work presented in this paper is to construct digital literacy competences for junior high school students in Taiwan using Fuzzy Delphi Method. It identified six dimensions, twenty-one sub-dimensions, and eighty-one competences out for building the learning materials and planning further experimental teaching.
\end{abstract}

Index Terms-Fuzzy Delphi method, digital literacy competences, junior high school.

\section{INTRODUCTION}

Though digital literacy is important on learning, living, and career developing, learning plans and outcomes of digital literacy do not be well addressed for junior high school students. Moreover, the students' prior knowledge and nature have not been discussed very well, too. In the paper, we studied self- efficacy, student engagement, and cognitive loading to determine digital literacy learning model for junior high school students. In addition, the model incorporates sufficient prior knowledge and subject frame for its completeness and comprehensiveness. In summary, the goal is to assist teachers to prepare well-organized teaching materials and to educate students with the well digital literacy competences.

To gain the goal, we planned a three-year project 2 to develop a complete teaching method, including constructing digital literacy competences and teaching materials as well as an experimental teaching in selected classrooms. In the first year, digital literacies for different grade students were definitely figure out. We determined indicators of digital literacy competences for junior high school students in Taiwan via rounds of Fuzzy Delphi Method. Six dimensions and twenty one sub-Dimensions are sketched out finally, and are summarized in the following.

This paper is organized as follow. Literatures review is described in Section II. Section III presents the methodology. Section IV is the results and conclusions of the study.

\section{LITERATURE REVIEW}

We briefly discussed the related literatures, including the Contents of digital literacy competence, fuzzy numbers, and Fuzzy Delphi Method, in this section.

\footnotetext{
Manuscript received April 9, 2016; revised June 15, 2016. This work is supported by Ministry of Science and Technology, R.O.C. under contract of 104-2511-S-241-008.

The authors are with the Dept. of Computer Science and Information Management Hungkuang University, Taiwan (R.O.C.) (e-mail: fgchen@gmail.com).
}

\section{A. Digital Literacy}

Digital literacy was first introduced in 1980s. However, it was only focus on computer knowledges, i.e., the ability to operate computers and software [1]. Gilster summarized that digital literacy is the skill, cognitive, and attitude of processing and communicating information and knowledge [2]. The definition of digital literacy is diverse, such that it can be treated as a skill, a process, a thought, or a practical manner. In spite of its diversity, all has a common that digital literacy is an essential for living in twenty-first century [3]. Since $2000,73 \%$ of teens have access Internet [4]. In sum, it needs to build a way to promo the digital literacy of junior high (or higher) school students and an evaluating method of the promotion effectiveness.

Besides, smart devices, social media, online courses, and learning materials are lunched nowadays such that the learning style, communication method, and cooperation manner are thoroughly changed. It means that teaching materials and methods should be met with the change for the students' learning. Educators need to think about that how to construct learners the abilities to process different information from Internet under such diverse environments [5]-[7]. Moreover, with the emerging digital learning technologies, digital literacy is important to life-long learning and development [8]. Digital literacy is a basic life skill, needed in current economic and information society, under such diverse environment [9]-[11]. It is essential to promo digital literacy because of people needs to adapt the change of environments, including information environment [11]. Information technology and media literacy is in the core literacy in fundamental education from elementary to high school in Taiwan. Undoubtedly, digital literacy is an important thing for students' learning and educating.

Although the student digital literacy is so important, studies show that it is hard to construct knowledge from different information sources via Internet by using critical and meaningful manners [12], [13]. Also, it cannot infer that students have the ability of effectively using information and communication by observing their behaviors on using networking or mobile phones in classrooms [14].

\section{B. Fuzzy Numbers}

Fuzzy sets were introduced by Zadeh in 1965 to manipulate data that possessing non-statistical uncertainties [15]. It provided formalized tools to mathematically represent vagueness and uncertainty for dealing problems with the imprecision intrinsic. A fuzzy set $\tilde{\mathrm{A}}$ is a collection of ordered pairs $\left(\mathrm{x}, \boldsymbol{\mu}_{\tilde{\mathrm{A}}}(\mathrm{x})\right)$ for $\mathrm{x} \in \mathrm{X}$. $\mathrm{X}$ is called the universe of discourse. $\boldsymbol{\mu}_{\tilde{\mathrm{A}}}(\mathrm{x}): \mathrm{X} \rightarrow[0,1]$ is the membership function.

According to the nature or shape of membership function, a fuzzy number can be classified in different ways, such as 
triangular fuzzy number (TFN), trapezoidal fuzzy number etc. The popular one is TFN, which is defined by a triplet using the notation $\tilde{\mathrm{A}} \rightarrow(\mathrm{a}, \mathrm{b}, \mathrm{c})$ and is shown in Fig. 1 .

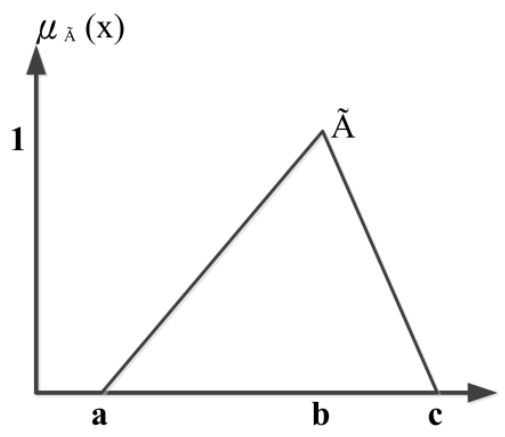

Fig. 1. Triangular Fuzzy Number.

\section{Fuzzy Delphi Method}

Generally the traditional Delphi Method needs several survey rounds to gain an acceptable standard. Ishikawa et.al introduced a modified Delphi Method by incorporating fuzzy set theory. The modified Delphi Method is named Fuzzy Delphi method [16]. Fuzzy Delphi Method was designed to solve the inherent uncertainty of the survey process. Applying Fuzzy Delphi Method to group decision can help to solve the fuzziness of common understanding of experts' opinions and to decrease the time of survey process. And, a TFN-based member function is used in Fuzzy Delphi Method.

The geometric mean was used to present the collective opinions from experts. It shows that the fuzzy weight number of expert $i$ on managerial competence item $\mathrm{j}$ in the equation 1 .

$$
\tilde{\mathrm{A}}_{i j}=\left(a_{i j}, b_{i j}, c_{i j}\right)
$$

where $i=1,2, \ldots, n$; and $j=1,2, \ldots, m$

Then the fuzzy weighting $\tilde{\mathrm{A}}_{j}$ of competence item $j$ is $\tilde{\mathrm{A}}_{j=}$ $\left(\mathrm{a}_{j}, \mathrm{~b}_{j}, \mathrm{c}_{j}\right), \mathrm{j}=1,2, . ., \mathrm{m}$.

$$
\begin{gathered}
a_{j}={ }_{j}^{\operatorname{Min}}\left\{a_{i j}\right\} \\
b_{j}=\frac{1}{n} \sum_{i=1}^{1} b_{i j} \\
c_{j}={ }_{j}^{\operatorname{Max}}\left\{c_{i j}\right\}
\end{gathered}
$$

The simple center of gravity method is used to defuzzify the fuzzy weight $\tilde{\mathrm{A}}_{j}$ of each selected competences to a definite value $\mathrm{S}_{j}$, which is shown in equation 5 .

$$
S_{j}=\frac{\left(a_{j}+b_{j}+c_{j}\right)}{3}
$$

The proper competences can be screened out from numerous competences by setting the threshold. The rule of the screening is as follows:

If $S j \geq \mathrm{a}, j$ competence is selected.

If $S j<\mathrm{a}, j$ competence is delete.

\section{Methordology}

\section{A. Research Design}

The work was organized systematically. It uses Fuzzy Delphi Method, focus group expert meeting, expert interview, and "Developing a Curriculum (DACUM)" expert meeting as well as all needed resources to do the research work.

\section{B. Summarize and Analysis Literature Surveys to Make} the Research Hypothesis and Framework

We have made a compete literature surveys on digital literacy, self-efficacy, learning engagement, cognitive load, digital learning material development strategy, cooperating learning, prior knowledge, cognitive style, and online testing and examination system. We figured the research hypothesis and its framework as in Fig. 2.

\section{Construct a Draft of Digital Literacy Item via Focus Group Expert Interviews}

5 experts in education/industry fields are invited to the focus group meeting for commenting the digital literacy ability items and make a draft of the ability items. The stage result is used as an input of DACUM expert meeting.

\section{Call a DACUM Expert Metting to Construct Digital Literacy Ability Items}

At this stage, 10 experts in education/industry fields are invited as the member of DACUM expert meeting to construct the digital literacy ability items.

\section{E. Using Survey to Confirm the Digital Literacy Ability Items}

10 experts in education/industry fields are invited to answer the survey of the digital literacy ability items using Fuzzy Delphi Method.

\section{F. Using Analytic Hierarchy Process (AHP) Survey to Gain the Weight of Thee Digital Literacy Ability Items}

We invited32 scholars/industry experts to answer the AHP survey of the weights of digital literacy ability items. Consequently the weight of digital literacy ability items was summarized out for the next stage of constructing teaching materials and scales.

\section{G. Fuzzy Delphi Questionnaire}

Table I shows that an element of Fuzzy Delphi Method

\begin{tabular}{|c|c|}
\hline \multirow{2}{*}{ Competences } & Required level \\
\hline & Very unimportant $\leftarrow \cdots \cdots \rightarrow$ very important \\
\hline $\begin{array}{l}\text { Can identify } \\
\text { common media }\end{array}$ & 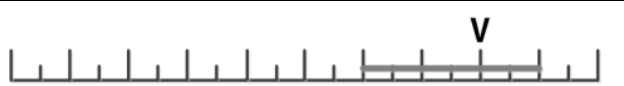 \\
\hline and concepts. & $\begin{array}{lllll}2 & 3 & 4 & 5 & 6\end{array}$ \\
\hline
\end{tabular}
Questionnaires, which was made in the study. 32 experts were invited to the process of commenting and revising the questionnaires.

TABLE I: SAMPLE FUZZY DELPHI METHOD QUESTIONNAIRE

\section{RESUlts AND CONCLUSIONS}

We used Fuzzy Delphi Method, to determine the digital literacy competences. The selected partial results were shown in Table II. There are six competence dimensions, 21 sub-dimensions, and 81 competences. The six competence dimensions are: (1) Communications and collaboration; (2) ICT literacy; (3) Career \& identity management; (4) Learning 
skills; (5) Information literacy; and (6) Media literacy. Based materials for the experimental teaching in the near future. on the results, we are doing the preparation of the teaching

TABLE II: SELECTED RESUlT OF THE DiGITAL LITERACY COMPETENCES

\begin{tabular}{|c|c|c|c|c|c|}
\hline $\begin{array}{l}\text { Sub- } \\
\text { dimension }\end{array}$ & Competences & $\mathbf{Z i}$ & Mi & Gi & $\begin{array}{l}\text { Select } \\
(\mathrm{Y} / \mathrm{N})\end{array}$ \\
\hline \multirow{6}{*}{$\begin{array}{l}\text { 1-1 Media } \\
\text { knowledge }\end{array}$} & 1 Can identify common media terminologies and concepts. & 3 & 3.47680273 & 6.036454 & $\mathrm{Y}$ \\
\hline & $\begin{array}{l}\text { 2. Can identify common media file formats, such as MP3, MPEG, AVI, WAV, } \\
\text { WMV, FLA. }\end{array}$ & 3 & 3.03717732 & 5.305528 & $\mathrm{Y}$ \\
\hline & 3. Can utilize drawing tools to express thoughts and ideas in a visual way. & 2 & 3.13780536 & 4.680702 & $\mathrm{~N}$ \\
\hline & $\begin{array}{l}\text { 4. Can explore and identify music, culture, drawing, sculpture to have international } \\
\text { perspective. }\end{array}$ & 0 & 2.86418981 & 4.35862 & $\mathrm{~N}$ \\
\hline & 5. Can evaluate the appropriateness and effectiveness of digital media. & 3 & 3.05060841 & 4.868666 & $\mathrm{~N}$ \\
\hline & 6. Can identify the require specification of generating media. & 2 & 2.95562341 & 4.223355 & $\mathrm{~N}$ \\
\hline \multirow{5}{*}{$\begin{array}{l}\text { 1-2 Media } \\
\text { appreciation }\end{array}$} & 1. Can enjoy the reading. & 1 & 3.29250626 & 6.724683 & Y \\
\hline & 2. Can express experiences on reading and enjoyment. & 3 & 3.21124733 & 6.161566 & $\mathrm{Y}$ \\
\hline & 3. Can read, watch, and enjoy media in multiple languages. & 2 & 3.26086029 & 5.261064 & $\mathrm{Y}$ \\
\hline & $\begin{array}{l}\text { 4. Can utilize digital tools and formats to improve the effectiveness on reading or } \\
\text { watching. }\end{array}$ & 2 & 2.91225342 & 4.560338 & $\mathrm{~N}$ \\
\hline & 5. Can evaluate media influences on learning, life, and social. & 1 & 3.00419638 & 4.402223 & $\mathrm{Y}$ \\
\hline \multirow{5}{*}{$\begin{array}{l}\text { 1-3 Media } \\
\text { Application }\end{array}$} & $\begin{array}{l}\text { 1. Can utilize drawing and briefing tools to express thoughts and ideas in a visual } \\
\text { way. }\end{array}$ & 0.5 & 3.08999466 & 5.08091 & Y \\
\hline & $\begin{array}{l}\text { 2. Can utilize tools, methods, and resources to exchange media information } \\
\text { effectively. }\end{array}$ & 2.5 & 2.9778936 & 5.255965 & $\mathrm{Y}$ \\
\hline & $\begin{array}{l}\text { 3. Can utilize mobile devices, scanner, digital album, and other digital devices to } \\
\text { digitalize, clip, paste, and store. }\end{array}$ & 1.5 & 3.29642698 & 6.039987 & $\mathrm{Y}$ \\
\hline & $\begin{array}{l}\text { 4. Can utilize mobile devices, scanner, digital camera, or other digital device to } \\
\text { import texts, figures, sounds, and movies into files, and vice versa. }\end{array}$ & 2 & 3.06575619 & 5.607275 & $\mathrm{Y}$ \\
\hline & $\begin{array}{l}\text { 5. Can utilize mobile devices, camera, camcorder, multimedia computer and media } \\
\text { process software to capture video clips, clip sounds, and make movies. }\end{array}$ & 2 & 2.79352872 & 5.021913 & Y \\
\hline
\end{tabular}

\section{REFERENCES}

[1] D. A. Norman, "Stages and levels in human-machine interaction," International Journal of Man-Machine Studies, vol. 21, pp. 365-375, Oct. 1984.

[2] P. Gilster, Digital Literacy, Wiley, 1998.

[3] W. W. F. Lau and A. H. K. Yuen, "Developing and validating of a perceived ICT literacy scale for junior secondary school students: Pedagogical and educational contributions," Comput. Educ., vol. 78, pp. 1-9, 2014.

[4] A. Lenhart, L. Rainie, and O. Lewis, "Teenage life online: The rise of the instant-message generation and the Internet's impact on friendships and family relationships," p. 46, 2001.

[5] P. A. Alexander et al., "Reading into the future: Competence for the 21st century," Educational Psychologist, vol. 47, pp. 259-280, 2012

[6] S. R. Goldman, J. L. G. Braasch, J. Wiley, A. C. Graesser, and K. Brodowinska, "Comprehending and learning from internet sources: Processing patterns of better and poorer learners," Reading Research Quarterly, vol. 47, pp. 356-381, 2012.

[7] D. J. Leu, H. Everett-Cacopardo, L. Zawilinski, G. McVerry, and W. I. O'Byrne, "New literacies of online reading comprehension," The Encyclopedia of Applied Linguistics, John Wiley \& Sons, Inc., 2012.

[8] S. Mohammadyari and H. Singh, "Understanding the effect of e-learning on individual performance: The role of digital literacy," Computers \& Education, vol. 82, pp. 11-25, 2015.

[9] A. Martin, "DigEuLit - A European framework for digital literacy: A progress report," Journal of eLiteracy, vol. 2, pp. 130-136, 2005.

[10] D. Bawden, "Information and digital literacies: A review of concepts," Journal of Documentation, vol. 57, pp. 218-259, 2001.
[11] S. Markless and D. Streatfield, Three Decades of Information Literacy: Redefining the Parameters, Change and Challenge: Information Literacy for the 21st Century, Auslib Press, 2007.

[12] A. Walraven, S. Brand-gruwel, and H. P. A. Boshuizen, "Information-problem solving: A review of problems students encounter and instructional solutions," Comput. Hum. Behav., vol. 24 pp. 623-648, 2008.

[13] Y. Eshet-Alkalai and E. Chajut, "Changes over time in digital literacy," Cyber Psychology \& Behavior, vol. 12, pp. 713-715, 2009.

[14] M. Thorell, P. K. Fridorff-Jens, P. Lassen, T. Lange, and L. Kayser, "Transforming students into digital academics: a challenge at both the individual and the institutional level," BMC Medical Education, vol. 15, pp. 1-10, 2015.

[15] L. A. Zadeh, "Fuzzy sets," Information and Control, vol. 8, pp 338-353, 1965.

[16] A. Ishikawa, M. Amagasa, T. Shiga, G. Tomizawa, R. Tatsuta, and H. Mieno, "The max-min Delphi method and fuzzy Delphi method via fuzzy integration," Fuzzy Sets and Systems, vol. 55, pp. 241-253, 1993.

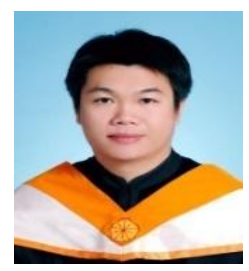

Fuh-Gwo Chen is an assistant professor in Hungkuang University. He received his Ph.D. in computer science from National Cheng Kung University, Taiwan. His current research interests include software engineering, healthcare information system, digital learning, Arduio programming, 3D printing systems, and virtual machine. 
Jr-Shian Chen is an assistant professor in Hungkuang University. He received his Ph.D. in information management graduate school of management from National Yunlin University of Science and Technology, Taiwan, the M.S. degree in information management from Providence University,

Taiwan. His current research interests include fuzzy time series, data mining, soft computing, and artificial

intelligence.

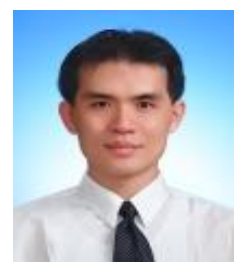

Jen-Ya Wang is an associate professor in the Department of Computer Science and Information Management at Hungkuang University. He received the Ph.D. degree in computer science and engineering from National Chung-Hsing University in 2009. His current research interests include optimization, algorithm, database system, patent search, medical image, and artificial intelligence.
David Wen-Shung Tai is a professor of the Dept. of Computer Science and Information Management, Hungkuang University, Taichung, Taiwan. He earned his MS degree from the Dept. of Industrial Technology at the Univ. of Wisconsin-Platteville in the USA. He also earned his MS degree from the Dept. of Computer Science at Iowa State University in the USA, and his $\mathrm{PhD}$ from the Department of Industrial Education and Technology at the same University in 1987. Prof. Tai's research experience included engineering education, e-learning, spatial ability and problem solving. 